\title{
Artigos
}

Thamirys Frigo Furtado'

Eliane Santana Dias Debus²

\section{A leitura literária na educação infantil: que espaços e tempos são estes?}

Resumo: Quando pensamos na formação de crianças-leitoras, é essencial refletirmos sobre espaço e tempo disponível para as ações pedagógicas que envolvem a leitura e a literatura. Sendo assim, este artigo apresenta discussões parciais realizadas em pesquisa de mestrado desenvolvida no âmbito do Programa de Pós-Graduação em Educação da Universidade Federal de Santa Catarina (UFSC), com o objetivo de mapear os espaços e tempos coletivos de leitura literária nas instituições de Educação Infantil da Rede Municipal de Ensino de Florianópolis (SC). A análise de dados nos levou a constatar que a maior parte das unidades possuem diferentes tempos $e$ espaços coletivos de leitura literária, organizados e planejados pelos próprios professores(as) e demais funcionários da instituição, considerando que não existe biblioteca em todas as instituições. Com isso, concluímos que há profissionais preocupados em aproximar as crianças da cultura letrada, participando ativamente da formação dos pequenos leitores, inventando e reinventando novas possibilidades a cada dia.

Palavras-chave: Espaço e tempo coletivo de leitura; Formação de crianças-leitoras; Leitura literária.

\section{Literary reading in child education: what spaces and times are these?}

Abstract: When thinking about the formation of children-readers, it is essential to reflect on time and space available for the pedagogical actions that involve reading and literature. Thus, this article presents partial discussions carried out in a master's degree research developed under the Post-Graduation Program in Education of the Federal University of Santa Catarina (UFSC), with the objective of map the collective time and space of literary reading in the Child Education Institutions of the Florianópolis Municipal School System (SC). Data analysis has led us to see that most of the units have different collective space and time of literary reading, organized and planned by the teachers and other staff of the institution, considering that there is no library in every institution. With this, we conclude that there are professionals concerned with bringing children closer to literate culture, actively participating in the training of small readers, inventing and reinventing new possibilities every day.

Keywords: Collective times and spaces of reading; Formation of children-readers; Literary reading.

\footnotetext{
${ }^{1}$ Mestre em Educação pela Universidade Federal de Santa Catarina (UFSC). Integrante do Grupo de Pesquisa em Literatura Infantil e Juvenil e práticas de mediação literária (LITERALISE/UFSC). Professora auxiliar de Educação Infantil da Rede Municipal de Ensino de Florianópolis (SC). E-mail: thamirysfrigo@hotmail.com

2 Doutora em Linguística e Letras pela Pontifícia Universidade Católica do Rio Grande do Sul. Líder do Grupo de Pesquisa em Literatura Infantil e Juvenil e práticas de mediação literária (LITERALISE/UFSC). Professora da Universidade Federal de Santa Catarina (UFSC), atuando no Departamento de Metodologia de Ensino e no Programa de pós-graduação em educação. E-mail: elianedebus@hotmail.com
} 


\section{Introdução}

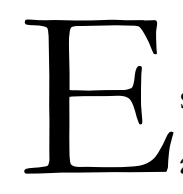

ste artigo apresenta discussões parciais realizadas em pesquisa de mestrado desenvolvida no âmbito do Programa de Pós-Graduação em Educação da Universidade Federal de Santa Catarina (UFSC). A pesquisa se sustenta na ampliação dos estudos referentes às práticas dos(as) professores(as) com crianças de 0 a $6^{3}$ anos de idade no que diz respeito à formação literária, entendendo este público como sujeitos leitores. Partindo do pressuposto que a mediação dos(as) professores(as) é essencial para o desenvolvimento das crianças, enfatizamos que é imprescindível que a ação pedagógica voltada a elas na Educação Infantil não se constitua ao ensino de conteúdos, mas se constitua em uma prática pedagógica que tenha em atenção às diferentes dimensões do desenvolvimento (intelectuais, expressivas, sociais, culturais, entre outras).

As discussões apresentadas na pesquisa dialogaram com alguns estudiosos como Magda Soares (2004; 2008; 2009), Luiz Percival Leme Britto (2005), Suely Amaral Mello (2010; 2012) e Mônica Correia Baptista (2010; 2013) no que diz respeito ao letramento e alfabetização; Rildo Cosson (2006; 2009) e Eliane Santana Dias Debus (2006; 2010) na discussão sobre letramento literário e leitura literária; Rosa Batista $(1998 ; 2001)$ e Maria da Graça Souza Horn (2007) no que se refere à organização do tempo e espaço na Educação Infantil; Mônica Correia Baptista (2012) e Yolanda Reyes (2010) nas discussões sobre leitura literária na primeira infância; e Eloisa Acires Candal Rocha (2008) no que se relaciona à criança e infância, entre outros estudiosos e documentos de referência da Educação Infantil

Quando falamos em formar leitores na Educação Infantil, não estamos propondo que crianças de 0 a 6 anos de idade possuam habilidades de codificação e decodificação do código gráfico, mas, sim, que desenvolvam um grau de letramento e uma proximidade com a cultura escrita. Partindo dessa perspectiva, entendemos o letramento como um processo "que tem início quando a criança começa a conviver com as diferentes manifestações da escrita na sociedade (...) e se prolonga por toda a vida, com crescente possibilidade de participação nas práticas sociais que envolvem a língua escrita" (VAL, 2006, p. 19). Portanto, a criança pode vivenciar práticas de letramento sem ser alfabetizada, e para que ocorram essas práticas é importante que sejam inseridas no dia a dia das crianças propostas que envolvam os usos sociais de leitura e escrita. No entanto, não podemos dissociar o letramento da alfabetização, pois ambos caminham juntos.

\footnotetext{
${ }_{3}^{3}$ Apesar de os documentos oficiais se referirem às instituições de Educação Infantil como instituições que educam e cuidam de crianças de 0 a 5 anos de idade, defendemos que esta etapa compreende de 0 a 6 anos, pois a Educação Infantil atende a crianças com 6 anos, como destaca as Diretrizes Curriculares Nacionais para a Educação Infantil (2010): "As crianças que completam 6 anos após o dia 31 de março devem ser matriculadas na Educação Infantil"(BRASIL, 2010, p15).
} 
Inserir a cultura letrada no cotidiano das crianças que frequentam a Educação Infantil por meio de práticas sociais de leitura e escrita como a leitura de diferentes tipos de textos (jornais, panfletos, revistas, livros infantis), assim como aproximar a criança da literatura apresentando-a de forma lúdica propiciam a entrada da criança ao mundo letrado, e consequentemente a descoberta da função social da leitura. É dessa forma que se inicia a formação do pequeno leitor, contribuindo para o gosto pela leitura e pela literatura em si.

Sendo assim, o intuito da pesquisa foi mapear os espaços e tempos coletivos de leitura em instituições de Educação Infantil da Rede Municipal de Ensino de Florianópolis (SC) buscando compreender quais são os tempos e espaços e materiais disponíveis para a prática literária; analisar o tempo e o espaço proposto para a inserção no mundo letrado das crianças que frequentam as instituições da Rede Municipal de Ensino de Florianópolis; perceber as estratégias e os recursos que são utilizados com as crianças para a formação de leitores; e analisar como os(as) profissionais responsáveis pelo espaço e tempo promovem o interesse das crianças pequenas pela leitura.

Para desenvolver o estudo proposto pela pesquisa seguimos um percurso quantitativo e qualitativo, o qual se efetiva no mapeamento realizado para levantar quais são os espaços coletivos de leitura literária encontrados em instituições de Educação infantil da Prefeitura Municipal de Florianópolis (PMF). Estas instituições são consideradas referência na Educação Infantil de Santa Catarina, por este motivo as selecionamos para a realização desta pesquisa.

A pesquisa teve início com o levantamento das unidades de Educação infantil atendidas pela PMF, a qual possui um total de 104 unidades. Destas, 54 são creches, 16 são instituições conveniadas e 34 são NEIs, sendo 10 NEIs vinculados. Reduzimos nosso campo de pesquisa para 78 unidades, retirando as 16 conveniadas, para nos focarmos somente nas unidades sob inteira responsabilidade da Prefeitura e os 10 NEIs vinculados, por estarem inseridos em instituições de Ensino Fundamental e já possuírem biblioteca.

A segunda etapa da pesquisa se constituiu por meio do encaminhamento de questionários para as instituições de Educação Infantil da PMF, com o intuito de responder questões sobre os tempos e espaços coletivos de leitura literária existentes. Os questionários foram encaminhados por malote para serem respondidos pelos diretores das unidades. Cabe destacar que supervisores e professores(as) também auxiliaram na pesquisa respondendo ao questionário.

O questionário proporcionou saber quais unidades possuem tempos e espaços coletivos de leitura literária, bem como compreender muitas questões que rodeiam estes tempos e espaços. Durante a pesquisa, a análise dos dados foi efetivada a partir de cinco categorias temáticas que envolvem as práticas de leitura literária no coletivo de uma unidade, quais sejam: os espaços e tempos diferenciados; os(as) profissionais responsáveis; o acervo; o planejamento; e os tempos e espaços coletivos de leitura literária. Portanto, esse artigo faz um recorte da pesquisa, apresentando e refletindo sobre os tempos e espaços diferenciados, destinados a leitura literária na Educação Infantil. 


\section{A leitura literária coletiva: Que tempos e espaços são estes?}

Para compreendermos um pouco mais sobre o contexto em que estão inseridas essas instituições no que se refere ao número de grupos e crianças atendidas, optamos por construir uma tabela demonstrativa destas quantidades. Como apresentado no quadro a seguir, observamos que das 71 unidades que responderam ao questionário, o número de grupos atendidos varia entre 2 e 20, assim como a diferença de uma instituição para outra é de 35 a 468 crianças atendidas na faixa de 0 a 6 anos.

Quadro I - Quantidades de grupos/crianças atendidos pelas unidades

\begin{tabular}{|l|l|l|}
\hline Quantidade de unidades & Grupos por unidade & Crianças por unidade \\
\hline 8 & 2 a 3 grupos & 35 a 60 crianças \\
\hline 13 & 4 a 5 grupos & 60 a 113 crianças \\
\hline 15 & 6 grupos & 72 a 220 crianças \\
\hline 13 & 7 a 8 grupos & 114 a 166 crianças \\
\hline 9 & 9 a 10 grupos & 176 a 207 crianças \\
\hline 7 & 11 a 12 grupos & 200 a 263 crianças \\
\hline 1 & 13 grupos & 251 crianças \\
\hline 2 & 15 grupos & 261 a 263 crianças \\
\hline 2 & 20 grupos & 370 a 410 crianças \\
\hline 1 & 22 grupos & 468 \\
\hline
\end{tabular}

A variação da quantidade de grupos atendidos pelas instituições e número de crianças é grande, o que consequentemente altera o espaço físico da unidade e o número de profissionais que trabalham na instituição. É importante ressaltar que independente do número de grupos ou crianças, as unidades possuem apenas um gestor. Todos esses fatores podem auxiliar ou não em propostas de organização de tempos e espaços coletivos, assim como em propostas voltadas para a leitura literária.

Com a crescente demanda das famílias por instituições de Educação Infantil, a prefeitura está ampliando algumas unidades e outras estão sendo construídas. De acordo com o site da prefeitura, o atendimento de crianças na faixa etária de 0 a 3 anos, pelo município, é de 47,5\%, aproximando-se da meta do Plano Nacional de Educação (PNE) $(\mathrm{PMF}, 2015)$. O que temos percebido nas instituições é que quanto maior o número de salas, mais difícil se torna o trabalho na unidade. Além disso, algumas unidades recebem ampliações de salas para receberem mais crianças, mas não são pensados novos espaços coletivos, como por exemplo ampliação do refeitório, bibliotecas, novas salas alternativas que possibilitem a interação das crianças com os tempos e espaços diferentes e com crianças de outros grupos.

${ }^{4}$ Meta 1: universalizar, até 2016, a educação infantil na pré-escola para as crianças de 4 (quatro) a 5 (cinco) anos de idade e ampliar a oferta de educação infantil em creches, de forma a atender, no mínimo, 50\% (cinquenta por cento) das crianças de até 3 (três) anos até o final da vigência deste PNE. (MEC/ SASE, 2014, p.9) 
O questionário proporcionou conhecer quais unidades possuem tempos e espaços coletivos de leitura literária. Inicialmente pretendíamos localizar quais e quantas unidades de Educação Infantil da PMF possuem biblioteca. No decorrer da pesquisa encontramos algumas unidades que possuíam outros espaços coletivos de leitura literária que não eram a biblioteca, chamados por nós de espaços diferenciados. Para melhor compreensão construímos um gráfico dividindo entre as instituições que possuem bibliotecas, as que possuem os espaços diferenciados, as que disponibilizam seu acervo apenas na sala de referência, e as que não possuem nenhum espaço coletivo de leitura literária.

Gráfico I - Tempos e espaços coletivos de leitura literária PMF

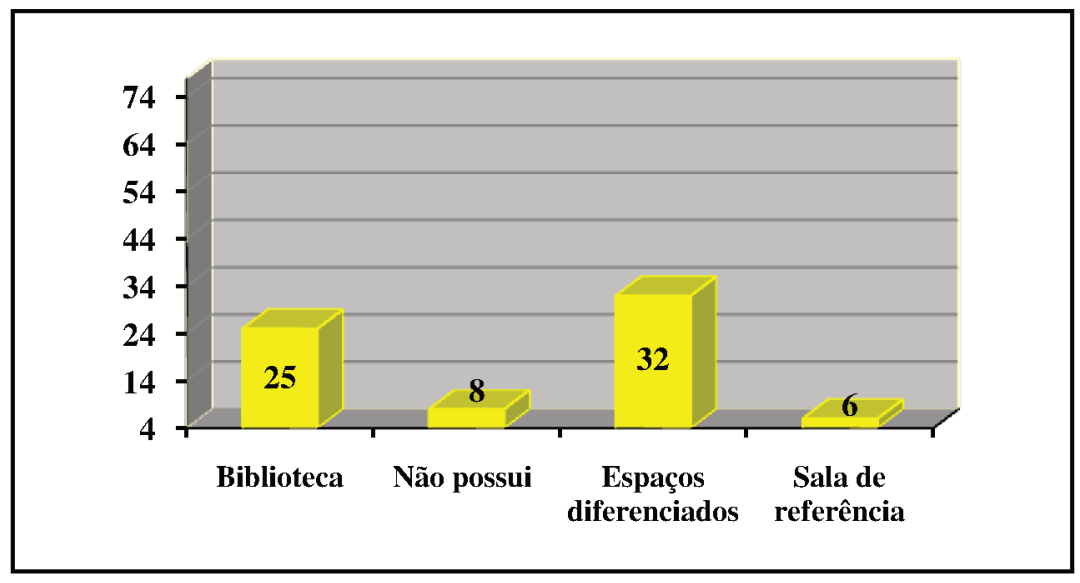

Fonte: Elaborado pela pesquisadora

Percebemos pelo gráfico acima que 8 unidades não dispõem de um espaço coletivo de leitura literária e 6 possuem livros apenas na sala de referência; 25 instituições têm biblioteca, sendo que algumas instituições contam também com outros espaços além da biblioteca, como brinquedoteca, cantinho de leitura, sala de vídeo, cantinho de leitura no refeitório e sala alternativa. Por fim, 32 instituições que não possuem biblioteca afirmam dispor de outros tempos espaços diferenciados como sala alternativa, cantinho de leitura e outros nomeados como biblioteca itinerante, brinquedoteca, Gibiteca, biblioteca ambulante, sala da imaginação, sala multiuso, biblioteca no Hall de entrada, carro de livros e sala de literatura.

Uma vez que optamos por não ir a campo conhecer esses espaços devido ao curto tempo de que dispúnhamos para a pesquisa, não temos a pretensão de detalhar como funcionam e como foram construídos esses tempos e espaços, ou seja, não sabemos afirmar se são "espaços de livros" ou "espaços de leitura", como defende Perrotti (2015a). Para Perrotti (2015a , p. 101), "espaços de livros não se transformam necessária e automaticamente em espaços de leitura", ou seja, necessitamos que este ambiente chame a atenção dos leitores e que ocorra uma mediação entre criança, espaço e livros, no qual a criança se apropria da cultura, diferente dos "espaços de livros", que se resume a um depósito de livros. A ideia inicial de conhecer esses tempos e espaços seria no sentido de saber se foram pensados após algum projeto dos próprios professores(as) ou construídos pela própria prefeitura. Entretanto, algumas unidades descreveram nos questionários sobre os seus tempos e espaços coletivos de leitura literária, ou projetos de 
leitura, contribuindo com o nosso conhecimento em relação às ações voltadas à cultura letrada que são propostas nas unidades pesquisadas.

A Creche Franklin Cascaes, localizada em Ponta das Canas, dispõe de uma biblioteca no hall, construída pelos profissionais da instituição. Ao responder ao questionário, o supervisor dessa unidade destaca que a biblioteca no hall de entrada foi recém inaugurada e que "A expectativa é que as crianças e as famílias a utilizem diariamente e que as professoras planejem momentos de exploração da biblioteca do hall da creche, assim como já fazem nas salas de referência e outros espaços externos" (Creche Franklin Cascaes, outubro de 2015).

Além da biblioteca no hall, a unidade conta também com o carro de livros (biblioteca itinerante). Com o intuito de compreender mais detalhes sobre esses projetos, encaminhamos e-mail para o supervisor e o diretor da unidade que nos relataram como eles funcionam: "Já tínhamos na creche (de anos anteriores) um carro de supermercado (que em 2014) foi reestruturado para ficar mais atrativo para as crianças, que tinha como objetivo funcionar como biblioteca itinerante, levando para cada sala livros diferentes daqueles que já tinham na sala referência.” (Creche Franklin Cascaes, março de 2016).

A instituição também gostaria de retomar o empréstimo de livros para as crianças e com isso surgiu a ideia, vinda de uma das professoras da unidade e aprovada pelo grupo em reunião pedagógica. Assim, a biblioteca no hall foi implantada em agosto de 2015 e transformada em uma ação pedagógica que seguia dois movimentos distintos, a criação da biblioteca do hall e o empréstimo dos livros para as crianças e famílias.

Com a ação implantada surgiu a inauguração desse espaço, demonstrando preocupação com a conscientização das crianças sobre a utilização da biblioteca no hall e o cuidado com o acervo exposto. Nesse sentido, o supervisor da unidade ressalta, em seu depoimento, que na inauguração do espaço foi realizada uma apresentação teatral por alguns profissionais que trouxeram, por meio das personagens, explicações para as crianças sobre como "essa ação seria operacionalizada, representando situações do cotidiano para enfatizar o cuidado necessário no manuseio dos livros" (Creche Franklin Cascaes, março de 2016).

No decorrer da proposta foi necessário realizar uma avaliação, e ao final do ano os(as) professores(as) e demais funcionários optaram pela continuidade do projeto no ano de 2016, destacando como pontos importantes a qualificação dos profissionais para o uso desse espaço e a revisão da forma como o empréstimo dos livros é realizado. Do depoimento inferimos uma preocupação com o manuseio do livro de modo desejante e não como algo mecânico, pois a intenção é a de "que continue mantendo neles o desejo de explorá-los e também para aguçar ainda mais a curiosidade das crianças, ou seja, para que seja significativo" (Creche Franklin Cascaes, março de 2016).

Percebendo o quanto esse projeto/ação envolveu as crianças de forma atrativa, o supervisor relata ainda que "Embora não tenha sido feita uma avaliação sistemática dessas ações para as crianças e famílias, de maneira geral um número de crianças obriga seus familiares a parar nesse espaço para explorá-lo na entrada e na saída da creche" (Creche Franklin Cascaes, março de 2016). Por esse relato podemos deduzir 
que o tempo e espaço propostos são tão significativos para as crianças que elas acabam fazendo uso deles até mesmo nos momentos em que não são apresentados por algum professor(a)/profissional da creche, assim como as famílias que chegam na creche para inscrição e matrícula.

São nesses momentos que os indicativos das crianças nos dizem sobre o trabalho realizado pelo(a) professor(a). Com o retorno delas, é possível perceber quando as ações fazem sentindo e trazem contribuições expressivas a elas. De acordo com o supervisor, com a retomada das atividades no ano de 2016, as famílias já questionavam quando os livros começariam a ir para casa novamente, demonstrando a importância desse projeto não apenas para os professores(as) e as crianças, mas também para as famílias envolvidas nessa ação. Por fim, o supervisor faz uma avaliação sobre a proposta da unidade de aproximar as crianças da cultura letrada por meio de uma biblioteca no hall.

[...] essa é uma ação que está tendo um resultado positivo e não temos a preocupação de preparar as crianças para serem futuros leitores, pois entendemos que elas já são. Nosso objetivo, nossa intenção é de que o contato/leitura com tais livros possa alimentar ainda mais a imaginação delas e assim contribuir com o desenvolvimento delas no que diz respeito as suas linguagens oral, escrita, sonoro-corporal, já que tais histórias mexem também com suas emoções e ampliam a possibilidade delas comunicarem-se em sociedade (Creche Franklin Cascaes, março de 2016).

Diante desse depoimento, é possível identificar que esses não são ambientes que foram construídos pela prefeitura com a finalidade de ser uma biblioteca, mas sim um tempo/espaço conhecido como o hall de entrada que se tornou um tempo/espaço coletivo de leitura literária, pensado pelos(as) professores(as) e demais profissionais daquela unidade. O exemplo nos mostra que existem profissionais preocupados com propostas que incluem as crianças na cultura letrada, e que mesmo sem uma biblioteca, sem o auxílio de um(a) professor(a) responsável, ou bibliotecário(a), é possível construir projetos, tempos e espaços coletivos de leitura literária. Além disso, o supervisor salienta que as crianças já são leitoras, ou seja, que a intenção não é prepará-las para serem futuros leitores, mas possibilitarem aos leitores o contato com a cultura letrada. Essa compreensão é fundamental para que possamos pensar nas ações pedagógicas que pretendemos desenvolver com os pequenos sujeitos. É preciso reconhecer que as crianças, apesar da sua pouca idade, já são leitoras.

Quando refletimos sobre livros, leitura, literatura, cultura letrada, letramento, alfabetização na Educação Infantil, destinamos automaticamente um tempo e espaço para a concretização destas propostas. Para Zen e Silveira (2012), predomina a fala de que pertence as famílias a tarefa de proporcionar aos seus filhos as primeiras leituras, instigando a curiosidade e o gosto pela literatura, “[...] mas é indiscutível que à escola, qualificada pedagogicamente para selecionar materiais adequados e abordar a riqueza da linguagem literária, cabe um trabalho mais sistematizado e um investimento mais amplo na formação do leitor" (ZEN; SILVEIRA, 2012, p. 51).

$\mathrm{Na}$ Educação Infantil a parceria com as famílias é fundamental para a construção de conhecimentos, e a ideia de aproximá-las da instituição e fazer com que elas contribuam e conheçam as ações realizadas pela instituição é essencial. $\mathrm{Na}$ Creche Franklin Cascaes encontramos esse processo, em que além das crianças, as famílias também se envolvem e são envolvidas no movimento de instigar nas 
crianças a curiosidade e o gosto pela leitura por meio de vivências e experiências com o objeto livro e o espaço de leitura. Acreditamos que esse é um exemplo a ser adotado: a participação das famílias no processo de aprendizagem de seus filhos.

Quanto aos investimentos importantes que destacamos estão os tempos e espaços coletivos de leitura literária pensados com e para as crianças, fundamentais na formação dos pequenos leitores, sejam eles disponibilizados e arquitetados pelos responsáveis pela construção da unidade ou pelos(as) professores(as) e demais funcionários da instituição. De acordo com Perrotti (2014, p. 131),

Espaços de leitura (cantos, salas, bibliotecas) são dispositivos de mediação cultural, no sentido a eles atribuído por Peraya (1999). Ao permitirem acesso à cultura, ao conhecimento, à informação, eles não só informam, mas formam. Possuem, portanto, uma dimensão pedagógica inerente, resultante das características próprias dos diferentes elementos que os constituem, das dinâmicas estabelecidas entre eles e das práticas concretas realizadas.

Por acreditarmos na importância da existência de tempos e de espaços de leitura literária, reafirmamos a necessidade de investir na construção de bibliotecas ou outros tempos e espaços diferenciados, como mencionam algumas unidades:

As práticas desenvolvidas nas salas de referência sempre contemplam o trabalho com a literatura infantil através de leitura de livros, contação de histórias, teatros, etc. Porém é necessária uma estrutura adequada na educação infantil, ou seja, investimento com um espaço (biblioteca) (Creche Doralice Teodora Bastos, agosto de 2015).

Gostaríamos de ter na Unidade um espaço próprio de biblioteca, com móveis planejados para este espaço onde os livros ficassem expostos e bem organizados (Creche Hermenegilda Carolina Jacques, agosto de 2015).

Constatamos, pelos comentários, que os profissionais sentem falta e se preocupam com a ausência desses tempos e espaços para a sua prática pedagógica, assim como com a organização destes tempos e espaços pensando na exposição dos livros, advertindo sobre a necessidade de investimento e estrutura adequada para um trabalho de qualidade com as crianças. Para este investimento inicialmente destacamos três pontos importantes: o tempo e o espaço propostos às crianças, o acervo disponível e o investimento em profissionais qualificados que atuem nesses tempos e espaços. Refletindo ainda sobre esse investimento, destacamos a importância do cuidado estético desses tempos e espaços, como expõe Perrotti (2014, p. 134):

O cuidado estético tem a ver com outras e mais importantes dimensões da vida, como a criação de vínculos, de relações do sujeito com o ambiente, com a mobilização de emoções e sentimentos. Desse modo, seja um canto ou uma pequena sala de leitura, seja uma biblioteca ampla, com diferentes e variados ambientes e recursos, há que se considerar, sempre, a qualidade estética do lugar.

Portanto a qualidade estética está além da aparência, ela está relacionada com todas as dimensões que formam esses tempos e espaços, ou seja, principalmente com a afinidade entre sujeito-ambiente e os sentimentos das crianças que se beneficiam com esses tempos e espaços. Para esse conjunto que forma a qualidade estética do ambiente é necessário profissionais responsáveis, planejamento e organização. 
Quando buscamos saber sobre os profissionais qualificados que atuam nestes tempos e espaços, descobrimos que nenhuma unidade possui bibliotecário(a), mas sim profissionais readaptados. No que se refere a estes responsáveis, a análise das respostas nos permitiram constatar que das 71 instituições, 38 possuem profissionais readaptados responsáveis pelo projeto/espaço de leitura e 26 não possuem nenhum profissional que auxilie neste espaço/projeto e 7 não responderam à pergunta.

É preciso realçar que nem todas as unidades possuem profissionais readaptados(as). Por esse fator, torna-se fundamental um(a) bibliotecário(a) que além de estar qualificado(a) para sua função, será $\mathrm{o}$ (a) responsável pelos projetos que envolvem a leitura e literatura na instituição. $\mathrm{O}$ (a) bibliotecário(a) tem como atribuições "planejar, organizar, gerenciar serviços, através de técnicas biblioteconômicas e promover ações visando a formação de leitores críticos e cidadãos plenos” (PMF, 2010).

Tendo em vista a função dos(as) bibliotecários(as), acreditamos nas grandes contribuições que esses profissionais poderiam trazer para a Educação Infantil e para a ampliação do repertório cultural das crianças e professores(as). É nesse momento que surge a dúvida sobre a razão de não termos bibliotecários(as) nas unidades de Educação Infantil da PMF. Visto que as unidades de Ensino Fundamental da PMF abrem concurso para tal cargo/função, onde está a diferença entre a Educação Infantil e o Ensino fundamental neste quesito?

É muito importante que se tenha uma biblioteca ou outro espaço coletivo de leitura literária nas unidades de Educação Infantil. No entanto, não podemos esquecer que para melhor funcionamento do espaço e aproveitamento das crianças leitoras necessitamos também de um responsável por este espaço, e principalmente de acervo suficiente para o número de crianças existentes em cada unidade.

Precisamos reconhecer que o investimento em livros realizado pelo Programa Nacional Biblioteca da Escola (PNBE) tem avançado com o passar dos anos. Como já citado anteriormente, desde 2008 temse incluído livros de Educação Infantil nesse programa, além do aumento gradativo do número de exemplares anualmente. Em sua dissertação, Souza (2015, p. 09) enfatiza que as políticas públicas voltadas ao livro e à leitura no Brasil "têm garantido resultados significativos quanto à distribuição e o acesso aos livros nas escolas públicas brasileiras e, também, têm contribuído para o crescimento do mercado editorial voltado para a literatura infantil". Com esse cenário constatamos a valorização da leitura voltada às crianças, em especial às que frequentam a Educação Infantil.

O encontro com o objeto livro torna-se de grande importância para o crescimento e o desenvolvimento da criança, motivo pelo qual deve estar ao seu alcance, possibilitando a escolha e a autonomia da criança. É importante ressaltar que o acesso da criança ao acervo, vai além do alcance ao objeto livro. Ter acesso aos livros, é além de tudo possibilitar este encontro de forma mediada pelo(a) professor(a), propondo constantes momentos desta descoberta, em um tempo e espaço organizado a partir da escuta da criança, no qual ela consegue se reconhecer e se sentir acolhida, pronta para uma leitura literária, priorizando o encontro com o livro. Contudo, algumas unidades da PMF ainda não disponibilizam o acervo para que as crianças tenham livre acesso, ou seja, apenas o adulto tem contato com ele, impossibilitando a criança de fazer sua leitura através dos cinco sentidos. 
Em nosso entendimento, não é suficiente possuirmos biblioteca se nossas crianças não tiverem livre acesso ao acervo. Uma das unidades destaca que há uma biblioteca na instituição, mas seu acervo não é de livre acesso às crianças. Logo, é importante repensar as práticas dentro das unidades de Educação Infantil, no sentido de que as crianças não sejam impedidas de tocarem nos livros e usufruírem de algo que é enviado para este fim. A discussão apresentada até aqui mostra unidades que não possuem biblioteca e defendem um investimento da PMF no que diz respeito a ter uma biblioteca, um acervo de qualidade e um profissional qualificado responsável por este tempo/espaço. Quando enfatizamos a importância desse investimento, estamos pensando na criança como a principal beneficiada; no entanto, quando possuímos esse tempo e espaço e privamos a criança de utilizá-lo, não estamos usufruindo desse tempo e espaço considerando nossas crianças como sujeitos de direitos.

Entendemos que para proporcionar o encontro da criança com a literatura infantil é necessário um planejamento que acompanhe este processo, ou seja, esta ida ao espaço diferenciado que aproxime as crianças da cultura letrada. Quando perguntamos se existe algum planejamento que antecede a ida ao espaço coletivo de leitura literária, 12 instituições responderam que às vezes, 45 que sim, 7 que não e 6 não responderam. Portanto, a maior parte das instituições/professores(as) planeja momentos de encontro entre crianças e livros. No entanto, é preciso considerar que ainda temos uma minoria que não planeja esses momentos. E assim nos indagamos se esses tempos e espaços são organizados e utilizados apenas como segundo plano das propostas dos(as) professores(as), ou qual seria o motivo de não serem planejados.

Uma das unidades relata que "O planejamento diário das educadoras contempla ações de incentivo e desenvolvimento do hábito de leitura e formação de novos leitores em todos os grupos" (Creche Orlandina Cordeiro, agosto de 2015). O depoimento enfatiza a importância do planejamento voltado a essas práticas na Educação Infantil. De acordo com Baptista (2013, p. 05), uma proposta que envolva a literatura, na Educação Infantil, “[...] ao respeitar a criança como produtora de cultura, assume um papel importante não apenas na formação de leitores, mas na própria constituição dos sujeitos. Ouvir, ler e contar histórias possibilita descobrir outros significados para a experiência humana".

As propostas relacionadas à leitura literária não só possibilitam novas experiências como também levam a criança a aprender mais sobre a realidade, a estar inserida nas questões que envolvem a sociedade e o meio social em que vive, auxiliam nas potencialidades de interpretação e compreensão. Por esse motivo necessitam estar presentes nos planejamentos dos(as) professores(as), visando à organização dos tempos e espaços dos livros a serem disponibilizados, como serão disponibilizados, e como será realizada a mediação durante a ação pedagógica.

Dentro das ações pedagógicas envolvendo a cultura letrada, previstas ou não nos planejamentos, realizadas ou não durante os imprevistos constantes nas unidades, identificamos algumas que chamam a atenção e que conhecemos no decorrer da leitura dos questionários. Apresentamos, na sequência, os projetos relacionados à leitura e as ações coletivas de leitura adotadas pelas unidades. 
- "Entre as diversas propostas que envolvem a leitura desenvolvemos os projetos coletivos como teatro realizado para e com as crianças e oficinas de histórias." (Creche Celso Pamplona, novembro de 2015);

- "Propomos/oferecemos para nossas crianças visita de contadores de histórias em vários momentos" (Nei Barreira do Janga, novembro de 2015);

- "Contação de história musicada realizada por mãe de criança" (NEI Colônia Z11, novembro de 2015);

- "Há contações de histórias sistematizadas pelas readaptadas da biblioteca" (Creche Waldemar da Silva Filho, novembro de 2015);

- "Projeto biblioteca móvel". O projeto "surgiu da necessidade de envolver as famílias nos momentos com seus filhos, qualificando estes momentos. [...]” (NEI Santo Antonio de Pádua, outubro de 2015);

- "Projeto bibliotecão, uma viagem ao mundo encantado das histórias" (Creche Marcelino Barcelos Dutra, agosto de 2015);

- Empréstimo de livros "Projeto de sala (por grupos): sacola viajante" (Creche Hermenegilda Carolina Jacques, agosto de 2015);

- "Na creche Altino existe o projeto Sacola literária com os 3 grupos. Tendo como objetivo o contato com o livro, o gosto pela literatura e desenvolvimento cultural. Esta sacola serve de biblioteca móvel [...]" (Creche Altino Dealtino Cabral, agosto de 2015);

- "Os grupos são contemplados com a visita da mala dos livros, casa dos livros e Baú dos livros, que durante o período existe um cronograma que possibilita duas vezes na semana o contato com as literaturas. E toda sexta-feira um grupo faz empréstimo para que a família acompanhe também esses momentos." (Creche Mateus de Barros, novembro de 2015);

- "Temos na secretaria um espaço para retirada de livros e também a biblioteca ambulante, onde as $5^{\circ} \mathrm{e}$ $6^{\circ}$ feiras as crianças escolhem livros para levar para casa"(Creche Doralice Teodora Bastos, outubro de 2015).

Dentre os projetos e ações apresentados, percebemos que em algumas unidades, além dos(as) professores(as) de sala e profissionais readaptados(as), a família também é envolvida nas ações pedagógicas. Isso nos permite dizer que a instituição preocupa-se com a importância da aproximação da família com a unidade e a participação dela na formação de seus filhos. Além das contações e teatros, grande parte das unidades preocupa-se também com o empréstimo dos livros, para que as crianças possam compartilhar as histórias com seus familiares e amigos.

\section{Os tempos e espaços coletivos de leitura literária}

Para finalizar nossa análise, construímos um mapa das unidades que possuem espaços coletivos de leitura literária, diferenciando com um livro amarelo as que possuem biblioteca, com uma estrela roxa as 
que possuem outros espaços coletivos de leitura literária, com um quadrado verde as que possuem livros apenas na sala de referência, com um losango azul as que não possuem espaço coletivo de leitura literária, e com um círculo marrom as unidades que não participaram da pesquisa.

Imagem I - Espaços e tempos coletivos de leitura PMF
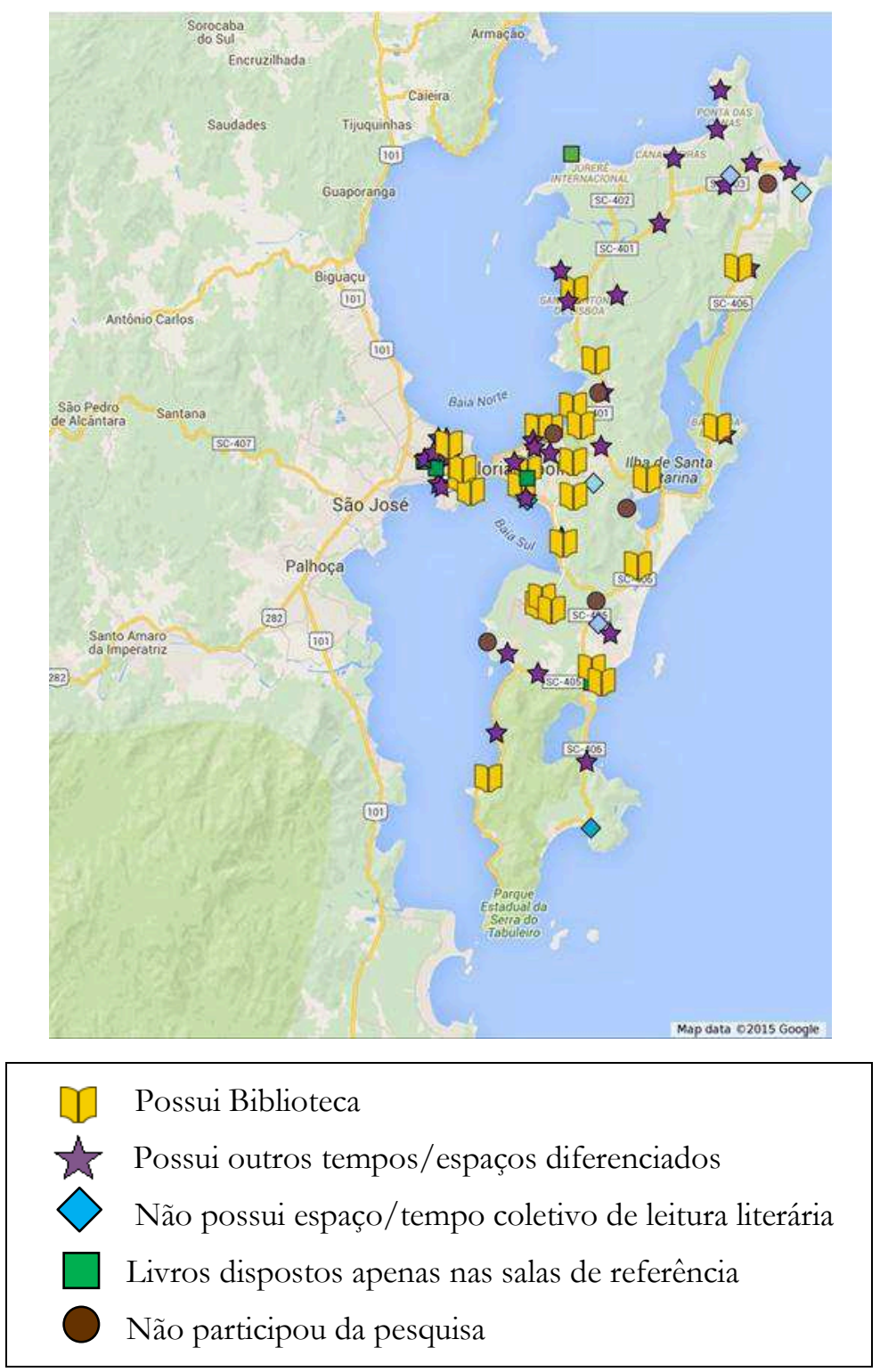

Fonte: Elaborada pela autora

Ao finalizar o mapeamento nos surpreendeu a quantidade de instituições que possuem biblioteca, pois no início da pesquisa acreditávamos que encontraríamos espaços coletivos de leitura literária dos mais diferenciados tipos, construídos pelos(as) próprios(as) professores(as) como recurso para propostas que incluíssem as crianças na cultura letrada, tentando suprir a falta de uma biblioteca. No entanto, descobrimos que apesar de não ser um número suficiente, por acreditarmos que todas as unidades deveriam ter uma biblioteca, 25 é um número considerável de bibliotecas nas unidades de Educação Infantil da PMF, bem como 32 unidades com tempos e espaços diferenciados torna-se um grande número 
de unidades engajadas e preocupadas com a formação dos pequenos leitores, quando comparado com a minoria que não disponibiliza de nenhum tempo/espaço voltado à leitura literária.

Perrotti (2015b, p. 103) nos auxilia na reflexão sobre continuarmos buscando uma educação infantil de qualidade, principalmente quando se refere à formação dos pequenos leitores. Para o autor, "O tempo confirma a importância de continuar apostando na formação de leitores, mesmo se as dificuldades para tanto continuem grandes [...] Daí a importância maior de continuarmos buscando compreensões essenciais a tal empreendimento", pois essas compreensões trazem consequências teóricas e práticas.

Seguindo essa linha de pensamento, acreditamos na formação dos pequenos leitores, e mesmo que as dificuldades apareçam, continuamos buscando compreender e colaborar com estas questões. Esperamos que esse mapeamento auxilie nas discussões referentes à formação de leitores nas unidades de Educação Infantil, bem como na construção, reforma e ampliação das próximas unidades para que sejam construídos espaços coletivos de leitura literária. Também acreditamos na importância da contratação de professores(as) ou bibliotecários(as) responsáveis por esses tempos e espaços, e na formação dos(as) professores(as) relacionada à leitura literária e à construção de projetos que envolvam a criança com a literatura, pensando na formação dos pequenos leitores.

\section{Considerações finais}

Quando pensamos na formação dos pequenos leitores, é essencial refletirmos sobre o espaço e tempo disponíveis/selecionados para as ações pedagógicas que envolvem a leitura e a literatura, tendo em vista que estes também são mediadores das ações de leitura. Com a organização dos diferenciados tempos e espaços coletivos de leitura literária, percebemos como temos profissionais preocupados em aproximar as crianças da cultura letrada, participando ativamente da formação dos pequenos leitores, inventando e reinventando novas possibilidades a cada dia. Assim como, localizamos instituições públicas realizando um trabalho de qualidade, no que se refere a formação dos pequenos sujeitos.

Entretanto, o que nos chamou atenção é a falta de profissionais qualificados que fiquem responsáveis unicamente por esses tempos/espaços. Mesmo as instituições que já possuem bibliotecas não dispõem de um(a) bibliotecário(a) responsável por esse tempo e espaço, o que nos leva a pensar o quanto a presença de um(a) professor(a) responsável ou bibliotecário(a) deixaria as propostas relacionadas à cultura letrada, assim como a organização dos tempos/espaços mais enriquecidas. Portanto, o porquê de as bibliotecas na Educação Infantil não possuírem um profissional responsável ainda é um questionamento não respondido nesta pesquisa.

Refletimos também sobre o acesso das crianças ao acervo nas unidades, e defendemos a importância do contato da criança com o livro, sem a preocupação de evitar sujá-los ou rasgá-los, tendo em vista que isso permite que a criança compreenda a função social do livro e como conservá-lo, ou seja, privarmos a criança do encontro com o livro é não oportunizar esse aprendizado. Portanto o acervo necessita estar ao alcance da criança, para a sua autonomia quanto à escolha de leitura, podendo escutar, 
tocar, sentir, cheirar, degustar, realizando a sua leitura ficcional (DEBUS, 2006). Partimos da ideia de que a criança, mesmo não lendo o código gráfico, já está em práticas sociais de leitura.

Quando falamos em um tempo e espaço coletivos de leitura literária nas instituições de Educação Infantil, estamos nos preocupando com a formação dos pequenos leitores desde os primeiros anos de vida e os benefícios que isso implicaria se pudéssemos contar com investimentos no que se refere ao profissional responsável, ao acervo disponível e a tudo o que engloba a organização desse tempo e espaço. Contudo, precisamos ter claro que o(a) professor(a), o registro, o planejamento e a organização desses momentos são tão importantes quanto qualquer um dos investimentos iniciais, pois eles serão os mediadores dessa ação, fundamentais para a formação leitora.

Entendemos que ser professor(a) na Educação Infantil é também preocupar-se com a formação dos pequenos leitores, criando e recriando os tempos e espaços, propostas para atrair cada vez mais a atenção das crianças, bem como preocupar-se com a estética e organização desses tempos e espaços, proporcionando autonomia, interação, atenção, imaginação, entre outras possibilidades presentes no dia a dia, ampliando as vivências e experiências das crianças.

Para finalizar, acreditamos que as discussões em diálogo com os estudiosos que sustentaram esta pesquisa nos mostraram o quando a literatura no cotidiano das crianças se torna importante no que diz respeito à formação de leitores, no desenvolvimento das crianças, nas habilidades conquistadas e nas experiências vivenciadas por meio desta aproximação. Por esse fator acreditamos na importância de tempos e espaços coletivos de leitura literária planejados e construídos com e para as crianças na Educação Infantil. 


\section{Referências}

BAPTISTA, Mônica Correia. Alfabetização e letramento em classes de crianças menores de sete anos. Texto apresentado no XV ENDIPE - Encontro Nacional de Didática e Prática de Ensino: Convergências e tensões no campo da formação e do trabalho docente: políticas e práticas educacionais, realizado em Belo Horizonte, MG, em junho de 2010

O lugar da linguagem escrita no currículo da educação infantil. In: FAVACHO, A. m. P.; PACHECO, J. A. \& SALES, S. R. Currículo: conhecimento e avaliação. Curitiba, PR: CRV, 2013. p. 209220.

Leitura literária na primeira infância: a experiência da bebeteca Can Butjosa em Barcelona. In: MACHADO, Maria Zélia Versiani. (Org.). A criança e a leitura literária: livros, espaços, mediações. Curitiba: Positivo. Rio de Janeiro: Fundação da Biblioteca Nacional, 2012.

BATISTA, Rosa. A rotina no dia a dia da creche: entre o proposto e o vivido. Dissertação de Mestrado em Educação. Universidade Federal de Santa Catarina. Florianópolis, 1998.

MG, 2001.

A rotina no dia a dia da creche: entre o proposto e o vivido. In: $24^{\mathrm{a}}$ ANPEd, Caxambu-

BRASIL. MEC. Diretrizes Curriculares Nacionais para Educação Infantil. Brasília: MEC/SEB, 2010.

BRITTOO, Luiz Percival Leme. Letramento e Alfabetização: Implicações para a Educação Infantil. In: FARIA, Ana Lucia Goulart de; MELLO, Suely Amaral (Orgs.). O Mundo da Escrita no Universo da Pequena Infância. São Paulo: Autores Associados, 2005.

COSSON, Rildo. Letramento Literário: teoria e prática. São Paulo: Contexto, 2006.

Letramento literário: para viver a literatura dentro e fora da escola. In: ZILBERMAN, Regina; ROSING, Tania M. K. (Orgs.). Escola e leitura: velha crise, novas alternativas. São Paulo: Global, 2009.

DEBUS, Eliane. Festaria de brincança: A leitura literária na Educação Infantil. São Paulo: Paulus, 2006.

Reflexões sobre os critérios de escolhas do livro literário nos anos iniciais do ensino fundamental. In: ROSING, Tania M. K.; BURLAMARQUE, Fabiane Verardi (Orgs.). De casa e de fora, de antes e de agora: estudos de literatura infantil e juvenil. Passo Fundo: Ed. Universidade de Passo Fundo, 2010.

HORN, Maria da Graça Souza. Sabores, cores, sons, aromas: a organização dos espaços na educação infantil. Porto Alegre: Artmed, 2007.

SOARES, Magda. Letramento e Alfabetização: as muitas facetas. Revista Brasileira de Educação, São Paulo: Autores Associados, v. 25, 2004. p. 5-17.

Livros para a educação infantil: A perspectiva editorial. In: PAIVA, Aparecida; SOARES, Magda (Orgs.). Literatura infantil: políticas e concepções. Belo Horizonte: Autêntica Editora, 2008.

O jogo das escolhas. In: MACHADO, Maria Zélia Versian (Org.). Escolhas (literárias) em jogo. Belo Horizonte: Ceale; Autêntica Editora, 2009. 
MEC/SASE. Planejando a Próxima Década. Conhecendo as 20 Metas do Plano Nacional de Educação, 2014. Disponível em: http://pne.mec.gov.br/images/pdf/pne_conhecendo_20_metas.pdf. $<$ Acesso em: 05 de junho de 2015>.

MELLO, Suely Amaral. Letramento e alfabetização na Educação Infantil, ou melhor, formação da atitude leitora e produtora de textos nas crianças pequenas. In: Educação Infantil e Sociedade: questões contemporâneas. Nova Petrópolis: Nova Harmonia, 2012, p. 75 a 87.

Contribuições da educação infantil para a formação do leitor e produtor de textos. In: PMF/SME. Diretrizes Educacionais Pedagógicas para a Educação Infantil. Florianópolis: Prelo Gráfica e Editora Ltda, 2010.

PERROTTI, Edmir. A organização dos espaços de leitura na Educação Infantil. In: BAPTISTA, Mônica Correia. et al.], (Orgs.) Literatura na educação infantil: acervos, espaços e mediações. Brasília: MEC, 2014.

Espaços de leitura/Leituras do espaço. Mesa redonda 3: Leitura Literária: espaços e mediação apresentado em: IV Congresso Internacional de Literatura Infantil e Juvenil. 02 a 04 de setembro de 2015; UNESP: Presidente Pudente, SP, 2015a.

Estações de leitura, dispositivos de mediação cultural e a luta pela palavra. In: Nuances: estudos sobre Educação. Presidente Prudente-SP, v. 26, n. 3, p. 93-112, set./dez. 2015b.

PMF. Cargos e atribuições bibliotecário. 2010. Disponível em: http://www.pmf.sc.gov.br/arquivos/arquivos/pdf/05 $02 \quad 2010$ 15.21.09.cbf55c8e66d1adbe261c6fc5427 37eaf.pdf. <Acesso em: 24 de abril de 2016>.

PMF. Educação Infantil tem reconhecimento mundial. 2015. Disponível em: http://www.pmf.sc.gov.br/entidades/educa/?pagina=notpagina\&menu=3\&noti=1480 <Acesso em: 25 de julho de 2015>.

REYES, Yolanda. A casa imaginária: Leitura e literatura na primeira infância. Trad. Marcia Frazão e Ronaldo Periassu. São Paulo: Global, 2010.

ROCHA, Eloisa Acires Candal. Por que ouvir as crianças? Algumas questões para um debate científico multidisciplinar. In: Silvia Helena Vieira Cruz (org.). A criança fala: a escuta de crianças em pesquisas. São Paulo: Cortez, 2008.

SOARES, Magda. O jogo das escolhas. In: MACHADO, Maria Zélia Versian (Org.). Escolhas (literárias) em jogo. Belo Horizonte: Ceale; Autêntica Editora, 2009.

SOUZA. Ingobert Vargas de. Políticas públicas para o livro e a leitura no Brasil: Acervos para os anos iniciais do Ensino Fundamental. Universidade Federal de Santa Catarina (Dissertação de Mestrado), Florianópolis, SC, 2015.

VAL, Maria da Graça Costa. O que é ser alfabetizado e letrado? In: CARVALHO, Maria Angélica Freire de; MENDONÇA, Rosa Helena (Orgs.). Práticas de leitura e escrita. Brasília: Ministério da Educação, 2006.

ZEN, Maria Isabel H. Dalla; SILVEIRA, Rosa M. Hessel. Surpresa, captura e envolvimento. Revista Educação: Literatura Infantil. São Paulo: Segmento V. único, p.51-61, 2012. 
Recebido em: 18/03/2016

Aprovado em: 03/04/2016 